\title{
(5)

\section{Developing a vaccine for leishmaniasis: how biology shapes policy}

GLOBAL HELSE

\section{KARL ERIK MÜLLER}

E-mail: karl.muller@uib.no

Karl Erik Müller (born 1982), medical doctor and research fellow at the Gade Research Group for Infection and Immunity, Department of Clinical Science, University of Bergen, and at the Institute of Biosciences, University of São Paulo, Brazil.

The author has completed the ICMJE form and reports no conflicts of interest.

\section{CARL TOLLEF SOLBERG}

Carl Tollef Solberg (born 1988), medical doctor, philosopher and research fellow at the Global Health Priorities research group, Department of Global Public Health and Primary Care, University of Bergen, and Centre for the Study of Mind in Nature (CSMN), Department of Philosophy, University of Oslo. The author has completed the ICMJE form and reports no conflicts of interest.

\section{JULIANA IDE AOKI}

Juliana Ide Aoki (born 1981), PhD, the Gade Research Group for Infection and Immunity, Department of Clinical Science, University of Bergen, and researcher at the Institute of Biosciences, Department of Physiology, University of São Paulo, Brazil.

The author has completed the ICMJE form and reports no conflicts of interest.

\section{LUCILE MARIA FLOETER-WINTER}

Lucile Maria Floeter-Winter (born 1951), PhD, professor of physiology and molecular biology at the Institute of Biosciences, Department of Physiology, University of São Paulo, Brazil. The author has completed the ICMJE form and reports no conflicts of interest.

\section{AUDUN HELGE NERLAND}

Audun Helge Nerland (born 1951), PhD, professor of microbiology and immunology at the Gade Research Group for Infection and Immunity, Department of Clinical Science, University of Bergen. The author has completed the ICMJE form and reports no conflicts of interest.

One aim of the Sustainable Development Goals is to end the epidemics of neglected tropical diseases by 2030. A multifaceted approach is needed to tackle leishmaniasis, keeping in mind the parasite, as well as its vector, host and reservoir. Attention should be focused on sustainable and achievable solutions rather than fairytale goals, and biology should play a more prominent role.

Leishmania is a highly adaptable parasite. At least 20 different species can cause the disease. Clinical manifestations include cutaneous (CL), mucocutaneous (MCL), visceral (VL, also 
known as kala-azar in Africa and Asia), and post-kala-azar dermal leishmaniasis (PKDL). Cutaneous leishmaniasis causes skin lesions that usually self-heal but may metastasise, causing scarring and stigmatisation. Mucocutaneous leishmaniasis may cause facial disfigurement. Visceral leishmaniasis affects organs such as the spleen, the liver and lymph nodes and, if left untreated, is fatal in $80-95 \%$ of patients (1). After treatment, post-kala-azar dermal leishmaniasis may develop with few or no symptoms, but patients are potentially harbouring parasites in the skin $(2,3)$. In addition, there are vast numbers of asymptomatic individuals who serve as reservoirs for the Leishmania parasite $(3,4)$.

Leishmaniasis is prevalent in 98 countries and endemic in some of the poorest regions of the world. Around 350 million people are at risk of infection (5). Annually, 200-400 ooo people are infected with visceral leishmaniasis, and 700 ooo-1 200 ooo with cutaneous leishmaniasis (5). Visceral leishmaniasis ranks second only behind malaria in terms of mortality caused by a parasitic disease. Risk factors for leishmaniasis include poverty, malnutrition, human migration and inadequate housing. In Europe, leishmaniasis is endemic in the Mediterranean region.

Almost 50 different sand fly species are known to transmit Leishmania $(6,7)$, and they exist in diverse environments, from the humid rainforests of Brazil to the dry climate in Afghanistan. Strategies to tackle the sand flies have so far not proven to be effective, and resistance to insecticides has been reported $(1,3)$.

Dogs and rodents are an important reservoir of Leishmania in several endemic areas. Dogs may be targeted using insecticide-impregnated dog collars, topically applied insecticide, drug therapy or vaccines, or more drastically, culling. However, all these measures have limited effect on human transmission and are impractical $(1,3)$. Drugs have limited usability in dogs, due to relapses and development of parasite resistance $(3,8)$. Questions have also been raised about the efficacy of the vaccines available for dogs in Europe and Brazil, especially on the effect of transmission from dog reservoir to humans $(1,8,9)$.

Furthermore, when the transmission involves wild animals, such as rodents, control of the animal reservoir is almost impossible. Crucially, the feasibility of vector and animal reservoir control programmes in poor resource settings is also questionable due to high costs and complexity of implementation (10).

\section{Fighting leishmaniasis}

Leishmaniasis, given its complex interplay between host, vector and reservoir, probably requires a multifaceted approach. Approaches to the vector and the animal reservoir have been discussed above. For humans, potential control strategies could include early detection, drugs and vaccine. Although dogs and rodents are important reservoirs in most endemic areas, there are areas such as India, where the transmission is thought to be anthroponotic, occurring only between humans. In these areas especially, early detection and treatment are essential to control leishmaniasis (11).

For humans, several of the available drugs have toxic side-effects, and parasite resistance has developed. In addition, long-term hospitalisation might be challenging in a low endemic setting. Therefore, in our opinion a vaccine is probably the best way forward, especially since infected people are known to acquire long-lasting immunity against infection from parasites of related strains $(1,3,10,12)$.

\section{A vaccine could work}

There are several unanswered questions concerning the development of vaccines for leishmaniasis. First, for which form of leishmaniasis is it most urgent to develop a vaccine? Ideally, a vaccine for leishmaniasis should be broadly protective against all the species of the parasite causing the different variants of clinical disease, but this has so far proven difficult. However, in theory, it should be possible. When selecting antigens for a recombinant, vector or nucleic acid vaccine, antigens that are highly conserved among 
different species of the pathogen are typically selected. Even if two species are relatively distant in evolutionary terms, a vaccine based on conserved antigens could give protection against several species. Intuitively, it may be most pressing to develop a vaccine for the potentially fatal visceral form, commonly caused by only two species $-L$. donovani or $L$. infantum.

Second, Leishmania has a complex digenetic life cycle between the mammalian host and the vector sand fly. The host-vector-reservoir relationship is only partly understood - making vaccine development more difficult. For example, when developing new vaccines, antigens that might enhance the susceptibility of the host to the infection have to be avoided (13). Likewise, a vaccine has to be tested for adverse effects among already infected individuals, such as what has been reported for the Q-fever vaccine $(14,15)$. Another example is the role of the sand fly and how it may affect the immune response in humans. This is only partly understood and may affect the efficacy of a vaccine (11). Furthermore, antibodies against Leishmania may facilitate infection rather than limit it $(13,16)$, also potentially complicating vaccine development.

Third, there is a debate about how the vaccine should work. Traditionally vaccines work prophylactically. But a vaccine could also work therapeutically, alone or in combination with drug therapy $(3,17)$. For leishmaniasis, it is unclear which approach is most viable and most important to prioritise.

Fourth, which type of vaccine is most likely to be effective against leishmaniasis? (See Table 1 for a brief overview of potential vaccine strategies and their pros and cons.) First generation vaccines include killed or live attenuated pathogens. Such vaccines have the potential to closely mimic natural infection. In the Middle East, so-called leishmanisation has been practised, whereby pus from cutaneous lesions and parasites from culture were used to induce a local infection (10). Leishmanisation was discontinued because of problems with reproducibility and safety issues. Furthermore, a leishmanisation strategy involving a viscerotropic strain, such as L. donovani, is highly unlikely.

\section{Table 1}

Potential vaccine strategies for leishmaniasis and their pros and cons

\begin{tabular}{|lcccc|}
\hline Vaccine approach & $\begin{array}{c}\text { Inducing } \\
\text { antibody } \\
\text { production }\end{array}$ & $\begin{array}{c}\text { Inducing } \\
\text { cellular } \\
\text { immunity }\end{array}$ & $\begin{array}{c}\text { Allows } \\
\text { diagnostic } \\
\text { testing }\end{array}$ & $\begin{array}{c}\text { Safe for } \\
\text { immuno- } \\
\text { suppressed } \\
\text { individuals }\end{array}$ \\
\hline Inactivated pathogen & Yes & No & No & Yes \\
\hline $\begin{array}{l}\text { Live attenuated } \\
\text { pathogen }\end{array}$ & Yes & Yes & No & No \\
\hline Recombinant antigens & Yes & No & Yes & Yes \\
\hline $\begin{array}{l}\text { Vector- based } \\
\text { vaccines }\end{array}$ & Yes & Yes & No & No \\
\hline Nucleic acid vaccine & Weak & Yes & Yes & Yes \\
\hline
\end{tabular}

To discriminate infected from vaccinated

${ }^{2}$ Includes both bacterial and viral vectors

${ }^{3}$ DNA, mRNA, RNA replicons

Moreover, ill-defined mutants may lack important epitopes necessary for protective immune responses, while at the same time carrying wild-type alleles that could potentially cause disease. The live attenuated approach is especially unattractive because endemic areas for leishmaniasis are also endemic for HIV and those infected with the latter are thereby also immunosuppressed. Another path would be to inactivate the parasite. However, there have been issues with standardisation of the culture from which the vaccine 
would be produced, and initial tests show that these vaccines give limited protection in humans (10).

Second generation vaccines are purified or recombinant proteins expressed in bacteria or eukaryotic cells. Such vaccines usually require an adjuvant to induce a good T-cell response (18). The Infectious Disease Research Institute in Seattle has developed a vaccine where several proteins conserved across several species of Leishmania are expressed in a single vaccine using a toll-like-receptor agonist as an adjuvant to induce a strong T-cell response $(18,19)$. This vaccine has shown promising results $(19)$.

Third generation vaccines are nucleic acid vaccines where expression vectors encoding for a protein antigen are introduced. Here not the antigen itself, but the information required to produce it, is introduced. The recipient's cells produce and present the antigens to immune cells (20). This vaccine strategy has obvious attractions, such as the fact that the vaccine can be rapidly and cheaply produced. The DNA-vaccine approach has been tested with several antigens against Leishmania-infected mice, but its effect remains unconvincing. Also, to the best of our knowledge, there are currently no pre-clinical or clinical trials using RNA-based vaccine technology for Leishmania. Vectors such as Adenovirus, expressing recombinant antigens, can also be used as vaccines. A novel vaccine uses this approach by expressing a gene encoding for two Leishmania proteins, and initial results are promising (17). But this is only in the phase I clinical trial stage, and there are significant challenges ahead.

It takes great effort to develop vaccines. So far, vaccine development has been carried out with limited information on the pathophysiological and immunological complexity of Leishmania infection.

Over the years, several vaccine targets and vaccination routes have been proposed and tested (21). Some of them have shown great potential in protecting animals against leishmaniasis (2). Remarkably few have been able to proceed to a clinical trial. This lack of progress is partly due to lack of a small-animal model that reflects human disease, and to the fact that many vaccines are tested with cutaneous strains where the testing has been undertaken by injections instead of sand fly bites (18).

\section{Policy and biology}

Leishmaniasis is one of the numerous examples of communicable diseases where the transition from laboratory testing to field trials has proved difficult. Researchers may put considerable efforts into optimising vaccine administration. By doing so, they risk removing themselves further from reality.

Many people with a risk of leishmaniasis infection live in areas that lack electricity supply and necessary infrastructure. How useful then is a vaccine that requires a cold-chain? And how beneficial is a vaccine that requires multiple boosts at specific time intervals, when there is a significant challenge in getting patients to the clinic? This is how a two-way approach between biology and policy comes into practice. In addition to a proper understanding of pathophysiology and immunology, an in-depth understanding of the dayto-day situation in several endemic areas is essential.

Currently, the World Health Organization classifies 20 communicable diseases and conditions as neglected tropical diseases (NTDs) (22). These neglected tropical diseases affect more than one billion people and cause high levels of morbidity and mortality $(9,22)$. Most neglected tropical diseases are treatable, and they are first and foremost diseases of the poor (22). The Global Burden of Disease study - a critical tool for monitoring global health and prioritising between health programmes - systematically undervalues the neglected tropical diseases (23).

According to Sustainable Development Goal 3, we should: 'end the epidemics of AIDS, tuberculosis, malaria and neglected tropical diseases and combat hepatitis, water-borne diseases and other communicable diseases' (24) by 2030. Much has been said about the 
hurdles in securing adequate funding for fighting neglected tropical diseases $(9,12)$. The market is not lucrative enough to recover the cost of developing vaccines (25). Therefore, there is a requirement for a need-based rather than a market-based approach.

In recent years, the neglected tropical diseases have received increased attention worldwide. Advances include the 2012 London Declaration (26), the Global Network for neglected tropical diseases (27) and several World Health Assembly resolutions (28). The development of drugs and vaccines for neglected tropical diseases is progressing, albeit slowly (29). This improvement includes the Drugs for Neglected Diseases Initiative (30), and other partnerships between industry, government and academic institutions such as BIO Ventures for Global Health (31) and the Tres Cantos Open Lab Foundation (32).

\section{Priority to biology}

Neglected tropical diseases are ignored in several ways: They are underreported, underestimated, underfunded and underprioritised (9). Although we applaud the initiatives to put neglected tropical diseases higher on the global agenda, through for example the Sustainable Development Goals, much remains to be done. There is a need for coordinated leadership if Sustainable Development Goal 3 is to be reached by 2030 . Attention should be focused on sustainable and achievable solutions rather than fairytale goals. In policy initiatives for fighting neglected tropical diseases, biology should have a more prominent role. One reason for this is the complexity in targeting the diseases and conditions that often require an in-depth knowledge of the intricacies of the biology of the pathogen and the host.

In this article we have given some insight into how a potentially effective preventive strategy has proven difficult for leishmaniasis and why that might be so. Partnership and cooperation between the public and private sectors must be strengthened, as Sustainable Development Goal 17 highlights. Significant advances could be ensured by improved collaboration between various actors and stakeholders to allow real translation from basic scientific research to the development of a commercially available protective vaccine for leishmaniasis.

\section{REFERENCES:}

1. Alvar J, Croft SL, Kaye P et al. Case study for a vaccine against leishmaniasis. Vaccine 2013; 31: 244 - 9. [PubMed][CrossRef]

2. Chappuis F, Sundar S, Hailu A et al. Visceral leishmaniasis: what are the needs for diagnosis, treatment and control? Nat Rev Microbiol 2007; 5: 873- 82. [PubMed][CrossRef]

3. Vallur AC, Duthie MS, Reinhart C et al. Biomarkers for intracellular pathogens: establishing tools as vaccine and therapeutic endpoints for visceral leishmaniasis. Clin Microbiol Infect 2014; 20: O374-83. [PubMed][CrossRef]

4. Alvar J, Vélez ID, Bern C et al. Leishmaniasis worldwide and global estimates of its incidence. PLoS One 2012; 7: e35671. [PubMed][CrossRef]

5. Galati EAB, Nunes VLB, Cristaldo G. Ecology of phlebotomines (Diptera: Psychodidae) in a visceral and cutaneous leishmaniosis focus in the Serra da Bodoquena and in an adjacent area of the state of Mato Grosso do Sul, Brazil. Rev Patol Trop 2003; 32: 235 - 61.

6. Lainson R, Shaw JJ. New World Leishmaniasis. In: Mahy BWJ, Meulen V ter, Borriello SP et al, ed. Topley \& Wilson's Microbiology and Microbial Infections. Chichester, UK: John Wiley \& Sons, Ltd, 2010. http://www3.interscience.wiley.com/cgi-bin/resolvedoi?DOI=10.1002/9780470688618.taw0182

(6.7.2017).

7. Stockdale L, Newton R. A review of preventative methods against human leishmaniasis infection. PLoS Negl Trop Dis 2013; 7: e2278. [PubMed][CrossRef]

8. Miró G, Petersen C, Cardoso L et al. Novel Areas for Prevention and Control of Canine Leishmaniosis. 
Trends Parasitol 2017; 33: 718 -30. [PubMed][CrossRef]

9. Welburn SC, Beange I, Ducrotoy MJ et al. The neglected zoonoses-the case for integrated control and advocacy. Clin Microbiol Infect 2015; 21: 433 - 43. [PubMed][CrossRef]

10. Noazin S, Modabber F, Khamesipour A et al. First generation leishmaniasis vaccines: a review of field efficacy trials. Vaccine 2008; 26: 6759 - 67. [PubMed][CrossRef]

11. Ready PD. Epidemiology of visceral leishmaniasis. Clin Epidemiol 2014; 6:147 - 54.

[PubMed][CrossRef]

12. Srivastava S, Shankar P, Mishra J et al. Possibilities and challenges for developing a successful vaccine for leishmaniasis. Parasit Vectors 2016; 9: 277. [PubMed][CrossRef]

13. Halstead SB, Mahalingam S, Marovich MA et al. Intrinsic antibody-dependent enhancement of microbial infection in macrophages: disease regulation by immune complexes. Lancet Infect Dis 2010; 10: 712 - 22. [PubMed][CrossRef]

14. Marmion B. A guide to $Q$ fever and $Q$ fever vaccination. CSL Biotherapies, 2009.

http://meatiesohs.org/files/Q_Fever_booklet.pdf(28.10.2017).

15. Schoffelen T, Wong A, Rümke HC et al. Adverse events and association with age, sex and immunological parameters of $Q$ fever vaccination in patients at risk for chronic $Q$ fever in the Netherlands 2011. Vaccine 2014; 32: 6622 -30. [PubMed][CrossRef]

16. Chu N, Thomas BN, Patel SR et al. IgG1 is pathogenic in Leishmania mexicana infection. J Immunol 2010; 185: 6939 - 46. [PubMed][CrossRef]

17. Osman M, Mistry A, Keding A et al. A third generation vaccine for human visceral leishmaniasis and post kala azar dermal leishmaniasis: First-in-human trial of ChAd63-KH. PLoS Negl Trop Dis 2017; 11: eooo5527. [PubMed][CrossRef]

18. Duthie MS, Raman VS, Piazza FM et al. The development and clinical evaluation of secondgeneration leishmaniasis vaccines. Vaccine 2012;30: 134 - 41. [PubMed][CrossRef]

19. Llanos-Cuentas A, Calderón W, Cruz M et al. A clinical trial to evaluate the safety and immunogenicity of the LEISH-F1+MPL-SE vaccine when used in combination with sodium stibogluconate for the treatment of mucosal leishmaniasis. Vaccine 2010; 28: 7427-35. [PubMed][CrossRef]

20. DeFrancesco L. The 'anti-hype’ vaccine. Nat Biotechnol 2017; 35: 193 - 7. [PubMed][CrossRef]

21. Jain K, Jain NK. Vaccines for visceral leishmaniasis: A review. J Immunol Methods 2015; 422: 1 - 12. [PubMed][CrossRef]

22. World Health Organization. Neglected Tropical Diseases. 2017.

http://www.who.int/neglected_diseases/diseases/en/(28.10.2017).

23. King CH, Bertino A-M. Asymmetries of Poverty: Why Global Burden of Disease Valuations

Underestimate the Burden of Neglected Tropical Diseases. Brooker S, editor. PLoS Negl Trop Dis 20o8; 2: e2o9.

24. United Nations. Transforming our World: The 2030 Agenda for Sustainable Development.

A/RES/70/1.2015.

https://sustainabledevelopment.un.org/content/documents/21252030\%20Agenda\%2ofor\%20Sustainabl e\%2oDevelopment\%2oweb.pdf(9.11.2017).

25. Costa CHN, Peters NC, Maruyama SR et al. Vaccines for the leishmaniases: proposals for a research agenda. PLoS Negl Trop Dis 2011; 5: e943. [PubMed][CrossRef]

26. Uniting to Combat Neglected Tropical Diseases. The London Declaration. 2017. http://unitingtocombatntds.org/london-declaration-neglected-tropical-diseases (9.11.2017).

27. Global Network for Neglected Tropical Diseases. Global Network for Neglected Tropical Diseases. 2017. http://www.sabin.org/programs/global-network-neglected-tropical-diseases-o (27.10.2017).

28. World Health Organization. World Health Assembly (WHA) Resolutions on Neglected Tropical Diseases: 1948-2013. 2017. http://www.who.int/neglected_diseases/mediacentre/resolutions/en/ (9.11.2017).

29. Pedrique B, Strub-Wourgaft N, Some C et al. The drug and vaccine landscape for neglected diseases 
(2000-11): a systematic assessment. Lancet Glob Health 2013; 1: e371 - 9. [PubMed][CrossRef]

30. Drugs for Neglected Diseases initiative. History - DNDi. 2017.

https://www.dndi.org/about-dndi/history/ (20.07.2017).

31. BIO Ventures for Global Health. BIO Ventures for Global Health - About BVGH. https://bvgh.org/ (30.10.2017)

32. Tres Cantos Open Lab Foundation. About the open lab.

http://www.openlabfoundation.org/about.html (30.10.2017).

Published: 25 December 2017. Tidsskr Nor Legeforen. DOI:10.4045/tidsskr.17.0620

Received 23.7.2017, first revision submitted 30.10.2017, accepted 9.11.2017.

(C) The Journal of the Norwegian Medical Association 2020. Downloaded from tidsskriftet.no 